Brit. J. industr. Med., 1961, 18, 216.

\title{
ANOSMIA IN ALKALINE BATTERY WORKERS
}

\author{
BY \\ R. G. ADAMS and NORMAN CRABTREE \\ From Alkaline Battery Company Limited, Redditch, and The United Birmingham Hospitals
}

(RECEIVED FOR PUBLICATION FEBRUARY 22, 1961)

\begin{abstract}
The sense of smell of 106 alkaline battery workmen exposed at their work to cadmium and nickel dust has been compared with a control group of 84 men matched for age. The battery workers reported significantly more anosmia than the controls (15\% to zero) and did less well in the phenol smelling test $(27 \cdot 3 \%$ to $4.8 \%)$. Cadmium proteinuria was found in 17 of the battery workers, 11 of whom showed virtual anosmia. Figures of recent concentrations of cadmium and nickel in the atmosphere are given. The noses of 85 battery workers and 75 controls were examined. Signs of non-specific chronic irritation were more frequent in the battery workers but no significant relationship was established between this appearance and the presence of anosmia. It is concluded that the anosmia is due to exposure to cadmium or nickel dust or a mixture of the two.
\end{abstract}

This is a study of olfactory acuity in a group of men employed in alkaline battery manufacture, and is divided into two parts. Part I reports on the incidence of anosmia, and Part II deals with the results of macroscopic examination of the men's noses. This was undertaken to determine whether specific changes could be observed in the nasal mucosa and whether these, if present, could be related to olfactory acuity.

Two powders are used in the manufacture of alkaline batteries: cadmium powder, which contains $60-64 \%$ of cadmium oxide and $16-18 \%$ of ferrous iron; and nickel powder, which contains $72 \%$ of nickel hydroxide and $18-20 \%$ of graphite.

Anosmia was first noted in this factory in 1948. In a survey at this time it was found that of 68 men examined, $13(19 \%)$ had anosmia and $18(26 \%)$ had proteinuria (C. L. Potts, personal communication). Shortly before this Friberg (1948) reported on his findings of proteinuria and emphysema in alkaline battery workers in Sweden; and he also noted that some of these men had anosmia. In his paper on emphysema and proteinuria in men casting coppercadmium alloys, Bonnell (1955) noted that some of the men complained of nasal soreness, but none of them appeared to have lost the sense of smell.

As a result of these discoveries, the men exposed to cadmium in this factory were offered annual medical examinations. During these examinations, which were started in 1956, particular attention was paid to renal, respiratory, and olfactory function.

\section{PART I}

The results in this part of the paper are taken from the records of the examinations carried out by one of us (R.G.A.) in 1958-1959. One hundred and six men were examined, six individuals being seen each week.

A control group was obtained in 1958 from a neighbouring engineering factory in which there was no specific hazard. The names of 100 men in this factory, in approximately the same distribution in five-year age groups as the battery workers, were randomly selected. Out of this group of 100,84 attended for examination.

\section{Olfactory Acuity}

In the absence of an objective test, the degree of olfactory acuity was measured by two methods.

(1) Each man was asked "What is your sense of smell like?", and the answer recorded as Good, Diminished, or None.

(2) A modification of the Proetz (1941) olfactometer. Phenol in liquid paraffin was the only substance used, the strength of different bottles being measured in olfacts. One olfact is defined as the minimum concentration of the substance in solution, which can be perceived by a large number of normal individuals, and the concentrations used were 1, 2 , $5,10,25,50,100$, and 200 olfacts of phenol. A man's olfactory acuity to phenol was recorded as the lowest concentration that he could detect. If he could not smell 200 olfacts his acuity was recorded 
TABLE 1a

BATTERY WORKERS

\begin{tabular}{|c|c|c|c|c|c|c|c|c|c|c|c|}
\hline & & \multicolumn{9}{|c|}{ Olfactory Acuity (in Olfacts of Phenol) } & \multirow{2}{*}{ Totals } \\
\hline & & 1 & 2 & 5 & 10 & 25 & 50 & 100 & 200 & $200+$ & \\
\hline $\begin{array}{l}\text { Symptomatic grades of } \\
\text { smelling }\end{array}$ & $\begin{array}{l}\text { Good } \\
\text { Diminished } \\
\text { None }\end{array}$ & $\begin{array}{r}15 \\
0 \\
0\end{array}$ & $\begin{array}{r}18 \\
0 \\
0\end{array}$ & $\begin{array}{r}13 \\
2 \\
0\end{array}$ & $\begin{array}{l}6 \\
2 \\
0\end{array}$ & $\begin{array}{l}7 \\
4 \\
0\end{array}$ & $\begin{array}{l}3 \\
1 \\
0\end{array}$ & $\begin{array}{l}2 \\
1 \\
0\end{array}$ & $\begin{array}{l}1 \\
2 \\
0\end{array}$ & $\begin{array}{r}2 \\
11 \\
16\end{array}$ & $\begin{array}{l}67 \\
23 \\
16\end{array}$ \\
\hline Totals & & 15 & 18 & 15 & 8 & 11 & 4 & 3 & 3 & 29 & 106 \\
\hline
\end{tabular}

TABLE $1 \mathrm{~b}$

CONTROL WORKERS

\begin{tabular}{|c|c|c|c|c|c|c|c|c|c|c|c|}
\hline & & \multicolumn{9}{|c|}{ Olfactory Acuity (in Olfacts of Phenol) } & \multirow{2}{*}{ Totals } \\
\hline & & 1 & 2 & 5 & 10 & 25 & 50 & 100 & 200 & $200+$ & \\
\hline $\begin{array}{l}\text { Symptomatic grades of } \\
\text { smelling }\end{array}$ & $\begin{array}{l}\text { Good } \\
\text { Diminished } \\
\text { None }\end{array}$ & $\begin{array}{r}17 \\
2 \\
0\end{array}$ & $\begin{array}{r}17 \\
1 \\
0\end{array}$ & $\begin{array}{r}18 \\
3 \\
0\end{array}$ & $\begin{array}{l}7 \\
3 \\
0\end{array}$ & $\begin{array}{l}4 \\
1 \\
0\end{array}$ & $\begin{array}{l}2 \\
2 \\
0\end{array}$ & $\begin{array}{l}1 \\
1 \\
0\end{array}$ & $\begin{array}{l}0 \\
1 \\
0\end{array}$ & $\begin{array}{l}1 \\
3 \\
0\end{array}$ & $\begin{array}{r}67 \\
17 \\
0\end{array}$ \\
\hline Totals & & 19 & 18 & 21 & 10 & 5 & 4 & 2 & 1 & 4 & 84 \\
\hline
\end{tabular}

as $200+$, and this was accepted as virtual anosmia. (No precautions were taken to ensure an odourless room, smoking was not prohibited before the test, crusts in the nose were not removed, and the nose was not treated with ephedrine in the presence of obstruction. The object of these modifications was to simplify the test for purposes of field study.)

\section{Results}

Table 1a shows how the battery workers in the three symptomatic grades responded to the smelling test.

The Table shows that there were 16 battery workers $(15 \%)$ who claimed to have no smell sense, all of whom had an acuity to phenol of $200+$. In all, there were 29 battery workers with acuity to phenol of $200+(27 \cdot 3 \%)$.

Of the 23 men who reported diminished smell sense, 11 had an acuity to phenol of $200+$ (i.e. virtual anosmia) suggesting that nearly half this group may have anosmia without realizing it. The remaining 12 responded to the phenol test in widely differing degrees, thus emphasizing the difficulty of assessing hyposmia quantitatively.
Table $1 \mathrm{~b}$ shows how the control workers in the three symptomatic grades responded to the smelling test.

From this Table it can be seen that none of the control workers claimed to have lost their sense of smell, as compared with 16 in the battery group. Seventeen of the control workers reported diminished smell sense, but only three of these had a phenol acuity of $200+$. In all there were four control workers with an acuity to phenol of $200+(4 \cdot 8 \%)$.

When the results in the two groups are compared, it is apparent that the alkaline battery workers reported significantly more anosmia than the control workers $(15 \%$ compared with $0 \%)$, and responded less well to the phenol test $(27 \cdot 3 \%$ with phenol acuity of $200+$ compared with $4.8 \%$ ).

Of the many factors which may affect the sense of smell, it was thought that smoking and age might be important, and these two factors were therefore studied. It was found that a greater proportion of the battery workers smoked, especially in the younger age groups. For statistical purposes, therefore, the most satisfactory comparison is made between smokers aged 35 and over.

TABLE 2

PERCENTAGE AGE DISTRIBUTION, SMOKERS AGED 35 AND OVER, AND MEAN NUMBER OF CIGARETTES PER SMOKER PER DAY

\begin{tabular}{|c|c|c|c|c|c|c|}
\hline \multirow[b]{2}{*}{ Age (Years) } & \multicolumn{3}{|c|}{ Controls } & \multicolumn{3}{|c|}{ Battery Workers } \\
\hline & No. & Per cent. & $\begin{array}{c}\text { Mean No. of } \\
\text { Cigarettes }\end{array}$ & No. & Per cent. & $\begin{array}{c}\text { Mean No. of } \\
\text { Cigarettes }\end{array}$ \\
\hline $\begin{array}{l}35 \text { to } 44 \\
45 \text { to } 54 \\
55 \text { and over }\end{array}$ & $\begin{array}{l}18 \\
18 \\
15\end{array}$ & $\begin{array}{l}35 \\
35 \\
29\end{array}$ & $\begin{array}{l}17 \cdot 2 \\
20 \cdot 8 \\
18 \cdot 3\end{array}$ & $\begin{array}{l}22 \\
25 \\
14\end{array}$ & $\begin{array}{l}36 \\
41 \\
23\end{array}$ & $\begin{array}{l}13.7 \\
16.9 \\
14.8\end{array}$ \\
\hline 35 and over & 51 & 100 & $18 \cdot 8$ & 61 & 100 & $15 \cdot 2$ \\
\hline
\end{tabular}


Table 2 shows that the controls smoked more than the battery workers. If any bias were introduced by these differences, it would tend to operate against finding a higher incidence of anosmia among the battery workers.

TABLE 3

ACUITY OF SMELL TO PHENOL AMONG SMOKERS AGED 35 AND OVER

\begin{tabular}{c|c|c}
\hline $\begin{array}{c}\text { Grades of Acuity } \\
\text { in Olfacts }\end{array}$ & Controls & Battery Workers \\
\hline $\begin{array}{c}1 \text { to } 5 \\
10 \text { to } 200\end{array}$ & 33 & 19 \\
$200+$ & 15 & 20 \\
\hline Totals & 3 & 61 \\
\hline
\end{tabular}

$\left(\mathrm{p}<0.001, x^{2}=16.9\right)$

The figures in Table 3 confirm the previous finding of more anosmia among the battery workers. The greater incidence, which is highly significant, cannot be attributed to differences in age or smoking habits.

Anosmia and Proteinuria.-The association between proteinuria and exposure to cadmium is established (Friberg, 1950; Smith, Kench, and Lane, 1955; Bonnell, 1955; Smith and Kench, 1957).

The properties of the protein in the urine of some of the workers in the factory in this study, have recently been investigated in great detail by Smith, Wells, and Kench (1961), and these authors confirm and add to the findings of Friberg and Bonnell.

Out of the 106 battery workers seen in 1958-1959, $17^{*}$ were found to have proteinuria (as shown by urine testing with $3 \%$ salicyl-sulphonic acid).

\section{Exposure}

In the process of alkaline battery manufacture it is important that the powders used should be very dry, and as a consequence the process is a dusty one. Contamination of the atmosphere is controlled by exhaust ventilation, and in this factory, extensive installations have been developed over the years.

Regular cadmium-in-air estimations have been carried out at fixed sites in the factory since 1957, and the results for the years 1957 and 1960 are shown below. These give an indication of the sort of conditions prevailing during the past four years. (Before 1957 the air sampling had not been carried out at exactly the same sites and the readings are not therefore comparable.)

Also shown below are the results of recent nickelin-air estimations from some similar sites, at which the nickel powder was worked.

\begin{tabular}{|c|c|c|}
\hline \multicolumn{2}{|c|}{$\begin{array}{l}\text { Cadmium-in-air } \\
\text { (mg. Cd/10 cu.m.) }\end{array}$} & $\begin{array}{c}\text { Nickel-in-air } \\
\text { (mg. Ni/10 cu.m.) }\end{array}$ \\
\hline 1957 & 1960 & 1960 \\
\hline $\begin{array}{r}27 \cdot 6 \\
1.60 \\
0.65 \\
16.90 \\
0.45 \\
0 \cdot 28 \\
3.70 \\
1 \cdot 40 \\
3.80 \\
2.20 \\
5.50 \\
3.60 \\
4.30 \\
5.70 \\
4.30 \\
-\end{array}$ & $\begin{array}{l}4.6 \\
4.10 \\
1 \cdot 18 \\
0.51 \\
0.78 \\
0.34 \\
6.65 \\
1.18 \\
1.82 \\
1.87 \\
1.44 \\
4.10 \\
0.41 \\
0.74 \\
1.24 \\
0.65\end{array}$ & $\begin{array}{l}\bar{Z} \\
0 \cdot 016 \\
0 \cdot 024 \\
0 \cdot 16 \\
0.016 \\
\bar{Z} \\
\overline{\bar{a}} \\
0.046 \\
0.56 \\
\bar{Z} \\
\overline{\bar{Z}} \\
0.042\end{array}$ \\
\hline
\end{tabular}

Of the 17 men with proteinuria, there were 11 who showed virtual anosmia to phenol, and 12 who claimed diminished or complete loss of smell. Of the 89 men without proteinuria, the corresponding figures were $18(20 \%)$ and $27(30 \%)$, and when compared with the previous figures, indicated a significant positive association between the incidence of proteinuria and anosmia (Table 4).

*One of these men, who was known to have been excreting protein for at least 10 years, was found to have normal renal function, after extensive investigations in the Department of Experimental Pathology, Queen Elizabeth Hospital, Birmingham.

TABLE 4

\begin{tabular}{l|c|c|c|c|c}
\hline \multirow{2}{*}{ Clinical Group } & No. of Men in & \multicolumn{2}{|c|}{ Virtual Anosmia to Phenol } & \multicolumn{2}{|c}{ Symptomatic Grading Diminished or None } \\
\cline { 2 - 5 } & & No. & Per cent. & No. & Per cent. \\
\hline $\begin{array}{l}\text { Proteinuria present } \\
\text { Proteinuria absent }\end{array}$ & 17 & 11 & 65 & 12 & 70 \\
\hline
\end{tabular}

The cadmium readings tend to be variable but the overall impression is that of a reduction in the amount of cadmium dust in 1960 compared with 1957. Both sets of cadmium readings are, however, considerably higher than those for nickel.

The length of exposure of the workers in this study varied from a few weeks to over 30 years, and 28 of the workers had been employed in a similar factory which closed down 13 years ago. Although no atmospheric monitoring was carried out in this factory, conditions were known to have been much dustier than in the present one. It is worth noting 
that 13 of these 28 workers had a phenol acuity of 200 , compared with 16 of the remaining 78 . The fact that these 28 men tended to be older than the rest of the group may have had some effect, but it is unlikely alone to account for the large difference. In addition 13 of the 17 men shown to have proteinuria, had worked in the factory which closed down. It does seem likely therefore, that many of the abnormalities found in this study were due to conditions unlike those obtaining today. These facts and suggestions are of no help in attempting to discover which of the ingredients of the two powders is responsible for producing anosmia, and no answer to this problem has been obtained.

\section{PART II}

\section{Changes in the Nasal Mucosa}

Ulceration of the nasal mucosa accompanied by burning sensations in a group of cadmium-platers was described by Mancioli (1940). The nasal passages were examined by one of us (N.L.C.) to see whether such changes existed in our series, whether they could be due to some specific action of powders to which alkaline battery workers are exposed, and related to the tendency to lose the sense of smell.

As an examination of this kind depends on a description of visible changes it was considered important that they be recorded by one individual examiner within a short space of time, and that at the time of the examination the examiner should not be unconsciously biased by knowing the identity of each man. Eighty-five workers and 75 control subjects were therefore presented at random in two sessions a few days apart at the end of 1958 .

Findings at Examination.-As with any sample of population there were variations in anatomy and signs of infection or allergy in varying degrees. Those which were clearly and recognizably due to non-specific causes were recorded but excluded from analysis.

In many cases, signs of irritation from inhaled material were found and recorded. Greyish dust was found on the mucosa in some cases where underlying pathology was not detected. In all cases the areas affected corresponded to the point at which the jet of inspired air impinged on the membrane, although this situation varied according to the detailed shape of the nasal passages. Where changes were seen the septum was involved in an oblique line corresponding to the air stream, the principal other sites being the anterior ends of the middle and inferior turbinate bones.

In mild cases there was a small localized area of
TABLE 5

\begin{tabular}{|c|c|c|c|c|}
\hline \multirow{2}{*}{ Workers } & \multicolumn{4}{|c|}{ Group } \\
\hline & $\mathbf{A}$ & B & $\mathrm{C}$ & Total \\
\hline $\begin{array}{l}\text { Battery } \\
\text { Control }\end{array}$ & $\begin{array}{l}36 \\
45\end{array}$ & $\begin{array}{l}43 \\
29\end{array}$ & $\begin{array}{l}5 \\
1\end{array}$ & $\begin{array}{l}84 \\
75\end{array}$ \\
\hline
\end{tabular}

whitening with slight thickening of the mucosa, indicating fibrosis beneath. The size varied from 0.5 to $3 \mathrm{~cm}$. In more advanced cases the centre was slightly depressed with shallow ulceration leading occasionally to the formation of dry crusting. In one case of prolonged exposure, very extensive dry crusting involving nearly all the nasal mucosa was seen. This was the only case in which any abnormality of the olfactory area in the upper one-third of the nasal cavity was detected, and here it was an extension of an even more marked atrophy and crusting of the respiratory portion of the mucosa. In no other case did the changes extend onto the olfactory area.

As an extension of this examination, and at another time, an area of affected mucosa was removed from a known battery worker. Microscopic examination by Dr. Brewer of the Pathological Department, University of Birmingham, showed a mild non-specific chronic inflammation of the submucosa with a few small loose focal accumulations of lymphocytes and a few widely scattered eosinophils.

Analysis of Clinical Findings.-According to the changes in the mucosa, cases were grouped into three categories.

A. No changes which could be ascribed to inhalation of irritant material.

B. Definite signs of irritation of a mild degree.

C. Marked changes unquestionably due to the inhalation of an irritant material producing definite destructive change.

Table 5 shows the distribution of battery and control workers in these three groups.

It is clear from the presence of control workers in the $B$ and $C$ Groups that the changes noted cannot be ascribed to irritation specifically from cadmium and nickel dusts. It is worth observing that there are more of the battery workers in Groups B and C than in Group A, but more of the control workers in Group A than in B and C, i.e. irritative changes in the nose are more common amongst the battery workers.

The relation of the phenol acuity in the alkaline battery workers to the presence of physical changes in the nose is shown in Table 6, the columns A, B, and $\mathrm{C}$ being the clinical groups previously described (five of the 84 individuals had not been tested for phenol acuity). 
TABLE 6

\begin{tabular}{c|c|c|c}
\hline Phenol Acuity & A & B & C \\
\hline 1 to 25 & 23 & 20 & 1 \\
50 to 200 & 1 & 6 & 0 \\
$200+$ & 10 & 14 & 4 \\
\hline
\end{tabular}

Analysis (by attaching an approximate logarithmic scale to the degrees of phenol acuity, where 1 corresponds to 0 and $200+$ corresponds to 8 ) shows that the mean olfactory sensitivity in the A Group is 3.62 and in the combined B and C Groups is 4.54 and is of no significance.

We can conclude that the presence of the changes described in the nasal mucosa are of no value in assessing the degree of hyposmia.

The relation of symptoms of diminished olfactory acuity to the physical changes, shown in Table 7 also show no significance (four of the 84 individuals had not been previously questioned on their sense of smell).

TABLE 7

\begin{tabular}{l|r|r|r}
\hline Olfactory Acuity & A & B & C \\
\cline { 2 - 4 } Good & 20 & 25 & 2 \\
Diminished & 7 & 9 & 1 \\
None & 7 & 7 & 2 \\
\hline
\end{tabular}

\section{DISCUSSION}

In the factory under examination it has been fairly common knowledge that "the powder irritates the nose", but in fact only two individuals have complained of or mentioned a sore nose during the course of medical examination; this in spite of the fact that attention has been directed towards the nose by questions about the sense of smell. This suggests that any such symptoms have been considered too trivial to mention.

To establish the existence of anosmia, or the degree of hyposmia is another matter, for there is no completely satisfactory and objective test of olfaction. We are dependent on a subjective test requiring the willing and unbiased co-operation of the individual. The phenol test used in this investigation appears to be a useful and repeatable clinical guide. It would be invalid under conditions where the individual might be tempted, consciously or unconsciously, to mislead. The corollary is equally true, that it would be impossible to prove the existence of the disability by such a subjective test.

Apart from the consistency and standardization of the strength of the odour, it is vital that the odour used should be detectable by olfaction alone, and not by taste or by irritation of the trigeminal nerve. We are accustomed by habit and convention to synthesize these three related sensations. The "taste" of food is a combination of taste and olfaction, and for the identification of ammonia the irritation of the trigeminal nerve is at least as important as, and certainly more dramatic than olfaction.

The phenol test has no value as a quantitative assessment of the degree of hyposmia. Most of the men with a good sense of smell were able to detect phenol in very high dilution, while many of those with diminished smell were unable to detect it even in the highest concentrations. It is interesting that the failure to detect phenol even in high concentration occurred in several men who were not aware of any significant disability.

Our findings show that exposure to alkaline battery dust can seriously impair the sense of smell, and also that there is a tendency towards changes of a chronic irritative nature in the nasal mucosa. It is quite clear, however, that these changes, while more common in the battery workers, are not specific, and their nature and degree are of no value in indicating the presence of anosmia.

Very few cases, even those with prolonged exposure, showed changes of a degree likely to cause any other disability. Irritation did not form a subject for complaint. In Mancioli's cases irritation, cough, dryness of the pharynx, bronchitis, and broncho-pneumonia, as well as gastrointestinal disturbances, were described. In only a few of the cases in our series, did the appearances in the nose correspond to those described by Mancioli.

The circumstances of their employment make it impossible to identify the particular ingredient in the dust that is responsible for the anosmia in the workers in this study. Iron oxide and graphite may be safely excluded since they are frequently encountered in industry, and anosmia has not been reported.

The reduction of the sense of smell in a large number of workers engaged on the production of nickel by an electrolytic process has recently been reported in Russia (Tatarskaya, 1960). This has not been reported elsewhere and as far as we have been able to determine in our inquiries, it has not been experienced in this country.

The positive correlation of anosmia with proteinuria in our series suggests that cadmium oxide is the offending dust, but it may well be that any irritant substance which is breathed for long periods either as a fine dust or aerosol can impair the sense of smell.

It is interesting to note that inhalation of cadmium fume affects the lower respiratory tract (Bonnell, 1955). The size of the particulate matter which is inhaled may be a factor influencing the site of the lesion, the larger particles of powder being held by 
the mucous blanket covering the nasal mucosa while the more finely particulate fume more readily reaches and affects the lungs.

We are indebted to Miss I. Dingwall Fordyce of the Department of Occupational Health, University of Manchester, for the statistical analyses in Part I; and to Dr. J. A. H. Waterhouse of the Department of Medical Statistics, University of Birmingham, for the statistical analyses in Part II.

We wish to record our gratitude to Dr. C. L. Potts, Appointed Factory Doctor in Redditch, who first noted the anosmia. He provided us with the opportunity to take part in this work, and has continued to guide and encourage us in the work, and in the preparation of this paper.

We wish to acknowledge the helpful advice and criticism received from Professor R. E. Lane, Professor of Occupational Health in the University of Manchester. We are grateful to the far-sightedness of the Management of Alkaline Batteries Ltd., who financed this study. We should particularly like to thank Mr. R. M. Blomfield, Works Manager and we also wish to record our gratitude to the nursing staff and employees of this factory.

Finally, we wish to thank Mr. J. A. Hunt, General Manager of the Hymatic Engineering Company, Ltd., and the employees of the factory who provided the control group.

\section{REFERENCES}

Bonnell, J. A. (1955). Brit. J. industr. Med., 12, 181. Friberg, L. (1948). J. industr. Hyg., 30, 32. (1950). Acta med. scand., 138, Suppl. 240. Mancioli, G. (1940). Rass. Med. industr., $11,632$.

Proetz, A. W. (1941). Essays on the Applied Physiology of the Nose. Annals Publishing Co., St. Louis, U.S.A.

Smith, J. C., and Kench, J. E. (1957). Brit. J. industr. Med., 14, 240. - , and Lane, R. E. (1955). Biochem. J., 61, 698. , Wells, A. R., and Kench, J. E. (1961). Brit. J. industr. Med., 18, 70 .

Tatarskaya, A. A. (1960). Gigiena Truda i Professional'nye Zabolebaniya., 4 , no. 6,35 . 